\title{
Fast HPLC-DAD Method for Estimation of Catechin for Standardization of Extracts and Antiasthmatic Polyherbal Formulations Containing Albizia lebbeck
}

\author{
Sonal Desai ${ }^{1}$, Pratima Tatke ${ }^{1 *}$, Vinay Gaitonde ${ }^{2}$, Satish Gabhe ${ }^{3}$ \\ ${ }^{1}$ Department of Pharmaceutical Chemistry, C. U. Shah College Of Pharmacy, S. N. D. T. Women's University, Santacruz (W), \\ Mumbai, Maharashtra, INDIA. \\ ${ }^{2}$ ProChrom India Pvt. Ltd., A/2, Varsha Milanl, Parsiwada Sahar Road, Andheri (E), Mumbai, Maharashtra, INDIA. \\ ${ }^{3}$ Department of Pharmaceutical Chemistry, Poona College of Pharmacy, Bharati Vidyapeeth Deemed University, Erandwane, \\ Pune, Maharashtra, INDIA.
}

\begin{abstract}
Background: Many marketed polyherbal formulations containing Albizia lebbeck are available for treatment of allergic disorders such as asthma and bronchitis. But these formulations are not standardized in terms of markers. The present work discusses development and validation of a new, simple and rapid HPLC-DAD method for quantification of phytomarker- catechin in methanol extracts for standardization of extracts and polyherbal formulations containing Albizia lebbeck. Materials and Methods: HPLC analysis was carried out using $C_{18}$ column $(100 \mathrm{~mm} \times 4.6 \mathrm{~mm}, 2.6 \mu \mathrm{m}) .0 .1 \%$ Phosphoric acid and acetonitrile in gradient mode was used as mobile phase. The column oven was equilibrated at $28^{\circ} \mathrm{C}$. The injection volume was $2 \mu \mathrm{l}$ and detection was carried out at $279 \mathrm{~nm}$. Results: The developed HPLC method was found to be linear over the range of $3.0-60 \mu \mathrm{g} / \mathrm{ml}$ with correlation coefficient of 0.9998 . The LOD and LOQ were found to be $1.0 \mu \mathrm{g} / \mathrm{ml}$ and $3.0 \mu \mathrm{g} / \mathrm{ml}$, respectively. The recovery of the catechin was between $97.12 \%-100.04 \%$. The low RSD values of intra and inter-day precision studies indicated good precision of the developed method. The method was found to be robust as small changes in method parameters did not significantly change peak symmetry and content of catechin. Conclusion: The developed method was sensitive, rapid and requires no special technique for sample preparation. The method was successfully applied for standardization of three bark extracts and marketed polyherbal formulations containing Albizia lebbeck.
\end{abstract}

Key words: Albizia lebbeck, Catechin, Fabaceae, HPLC, Shirish.

\section{INTRODUCTION}

Many medicinal plants are available in Ayurvedic and Unani system of medicines for the treatment of allergic disorders. Albizia lebbeck, belonging to Fabaceae family, is one of them. ${ }^{1}$ It is commonly known as Shirish. Stem bark of this plant contains condensed tannins, catechin, isomer of leucocyanidin, melacacidin, leuco-anthracyanidin, lebbecacidin, friedelin, $\beta$-sitosterol, betulinic acid and its glycosides, albizzia saponins $\mathrm{A}, \mathrm{B}$ and C. Bark also contains phenolic glycoside, albizinin and anthraquinone glycosides. ${ }^{2}$ Catechin is phytomarker present in bark of Albizia lebbeck and having antiallergic activity. ${ }^{3,4}$ It is chemically, (2R,3S)-2(3,4-dihydroxyphenyl)-3,4-dihydro-2Hchromene-3,5,7-triol belongs to the group of flavan-3-ols. Numbers of HPLC methods have also been reported for quantitative determination of catechin alone or in combination in different medicinal plants, biological fluids and Ayurvedic formulations. ${ }^{5-14}$ But no HPLC method has been developed and validated for catechin present in bark extract of Albizia lebbeck. Thus, the present work aims to develop and validate an HPLC-DAD method for the
Submission Date: 25-08-2019; Revision Date: 27-02-20; Accepted Date: 29-06-2020

DOI: 10.5530/ijper.54.3.103 Correspondence: Dr. Pratima Tatke

Principal and Professor of Pharmaceutical Chemistry, C. U. Shah College of Pharmacy, SNDT Women's University, Santacruz(w), Mumbai-400 049, Maharashtra, INDIA. Phone: +91 02226608551 E-mail: patatke@gmail.com

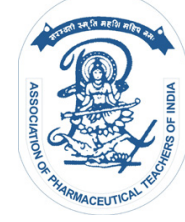

www.ijper.org 
determination of catechin in stem bark extract of Albizia lebbeck for succeeding application in standardization of extracts and anti-asthamatic polyherbal formulations containing Albizia lebbeck.

\section{MATERIALS AND METHODS}

\section{Chemicals and reagents}

Reference standard of catechin (Purity 98\% w/w) was purchased from Sigma-Aldrich Pvt. Ltd., Mumbai, India. Marketed polyherbal formulations containing Albizia lebbeck were purchased from local market of Mumbai, India. All the solvents and purified water were of HPLC grade from S. D. Fine chemicals, Mumbai, India. All the solutions were filtered through $0.2 \mu$ PTFE filter (Goettingen, Germany). Three different samples of stem bark of Albizia lebbeck were collected from Mumbai, Maharashtra, Valsad district of Gujarat and Tirunelvelli district of Tamil Nadu in February 2012 and authenticated at Botanical Survey of India, Pune, India.

\section{Instruments}

HPLC system used was Dionex-UltiMate 3000 (Germany) consisting of auto-sampler, quaternary pumps, column oven and diode array detector. All data were analysed using Chromeleon software version 6.80.

\section{Method development}

Various organic solvents like methanol or acetonitrile were tried in different ratio with aqueous solvents such as water or aqueous acids in isocratic mode as mobile phase. Effects of these solvents on responses such as retention time $\left(R_{t}\right)$, resolution (Rs), number of plates (N) and peak asymmetry (As) were evaluated. Mobile phase modifier TFA was used as ion pairing agent to produce sharper peaks. In all cases, no separation of components was observed in sample. Therefore it was decided to change mobile phase polarity with time to elute components of varying polarity. When gradient elution with methanol and aqueous acids was tried, a bulge in base line was observed. Hence, methanol was replaced by acetonitrile. Effect of acetonitrile in gradient mode with $0.1 \%$ TFA, $0.1 \%$ acetic acid or $0.1 \%$ phosphoric acid on chromatographic parameters was checked. In all cases, a hump in the leading edge of the peak of standard catechin was observed. Hence, a specialized column involving core shell technology, Sunshell $\mathrm{C}_{18}(100 \mathrm{~mm}$ X $4.6 \mathrm{~mm}$ I.D., $2.6 \mu \mathrm{m})$ from ChromaNik Technologies Ltd was selected for further analysis. Acetonitrile with $0.1 \%$ phosphoric acid in different gradient elution modes was used as mobile phase. Sample volume was $2 \mu \mathrm{l}$.
Column oven was equilibrated at temperature of $28^{\circ} \mathrm{C}$ and mobile phase was pumped at flow rate of $2.0 \mathrm{ml} / \mathrm{min}$ leading to less elution time of catechin without loss of resolution of peaks.

\section{Chromatographic conditions}

HPLC analysis was carried out using Sunshell $C_{18}$ column (100 mm X $4.6 \mathrm{~mm}, 2.6 \mu \mathrm{m})$ (ChromaNik Technologies Ltd). The column oven was equilibrated at $28^{\circ} \mathrm{C}$. The injection volume was $2.0 \mu \mathrm{l}$ and detection was carried out at $279 \mathrm{~nm}$. The mobile phase consisted of $0.1 \%$ Phosphoric acid (A) and acetonitrile (B) using a gradient elution of $10 \%$ to $15 \% \mathrm{~B}$ at 0 to $7 \mathrm{~min}$ and again $10 \% \mathrm{~B}$ at 7 to $9 \mathrm{~min}$.

\section{Preparation of standard solution}

Catechin (100 mg) was dissolved in $100 \mathrm{ml}$ of methanol by sonication for $10 \mathrm{~min}$ to prepare a stock solution of $1000 \mu \mathrm{g} / \mathrm{ml}$. From this, various aliquots were taken and diluted with appropriate volume of methanol to produce different concentrations. These concentrations were used for validation studies.

\section{Preparation of sample solution}

Albizia lebbeck dry stem bark powder (20 g)was defatted with $3 \times 200 \mathrm{ml}$ of petroleum ether $\left(60-80^{\circ} \mathrm{C}\right)$ by maceration for $24 \mathrm{hr}$. The petroleum ether extract was discarded and remaining plant material was macerated with $3 \times 200 \mathrm{ml}$ of methanol. Methanol extracts thus obtained were pooled together. The methanol extract was dried under reduced pressure using rotary evaporator. Methanol extract $(25 \mathrm{mg}$ ) thus obtained was dissolved in $10 \mathrm{ml}$ of methanol, sonicated for $5 \mathrm{~min}$ and filtered through $0.2 \mu$ PTFE filter.

\section{Preparation of sample solutions for analysis of formulations}

\section{Granules}

Accurately weighed $10.192 \mathrm{~g}$ of granules were macerated with $100 \mathrm{ml}$ of methanol and stirred at room temperature for $24 \mathrm{hr}$. The resulting solution was filtered and evaporated to dryness. Accurately weighed $0.1034 \mathrm{~g}$ of methanol extract thus obtained was dissolved in 10 $\mathrm{ml}$ of methanol and sonicated for $10 \mathrm{~min}$. The solution was filtered and injected in HPLC.

\section{Herbal tea}

Accurately weighed $10.348 \mathrm{~g}$ of herbal tea was macerated with $100 \mathrm{ml}$ of methanol and stirred at room temperature for $24 \mathrm{hr}$. The resulting solution was filtered and evaporated to dryness. Accurately weighed $0.1012 \mathrm{~g}$ of methanol extract thus obtained was dissolved in $10 \mathrm{ml}$ 
of methanol and sonicated for $10 \mathrm{~min}$. The solution was filtered and injected in HPLC.

\section{Vati}

Twenty Vatis were individually weighed; their mean weight was determined and the Vatis were triturated. Accurately weighed $8.765 \mathrm{~g}$ of Vati powder was macerated with $100 \mathrm{ml}$ of methanol and stirred at room temperature for $24 \mathrm{hr}$. The resulting solution was filtered and evaporated to dryness. Accurately weighed $0.1020 \mathrm{~g}$ of methanol extract thus obtained was dissolved in $10 \mathrm{ml}$ of methanol and sonicated for $10 \mathrm{~min}$. The solution was filtered and injected in HPLC.

\section{Syrup}

Accurately measured $50 \mathrm{ml}$ of syrup was extracted 3 $\times 100 \mathrm{ml}$ of methanol. The methanol extract was concentrated to dryness. Accurately weighed $0.1018 \mathrm{~g}$ of methanol extract thus obtained was dissolved in 10 $\mathrm{ml}$ of methanol and sonicated for $10 \mathrm{~min}$. The solution was filtered and injected in HPLC.

\section{Method Validation}

The developed method was validated for various parameters such as linearity, LOD, LOQ, accuracy, precision and system suitability as per ICH guidelines. ${ }^{15}$ Linear relationship between concentration and area was evaluated over the range $3.0-60 \mu \mathrm{g} / \mathrm{ml}$. Duplicate injections using $2.0 \mu \mathrm{l}$ loop were applied and detection was carried out at $279 \mathrm{~nm}$. Average area was determined. Graph of area Vs concentration was obtained and $R^{2}$ was calculated. The LOD and LOQ were calculated based on signal to noise ratio method. Catechin solutions in increasing concentrations were injected until signal to noise ratio of 3.0 and 10.0 were obtained for determination of LOD and LOQ, respectively. Known amount of sample was spiked with 32, 40 and $48 \mu \mathrm{g} /$ $\mathrm{ml}$ of the standard solutions of catechin separately and $\%$ recovery was calculated. Repeatability (intraday) and intermediate precision (interday) were determined through triplicate injections of methanol extract at three levels that is $80 \%, 100 \%$ and $120 \%$ (20 mg, $25 \mathrm{mg}$ and $30 \mathrm{mg}$ of methanol extract in $10 \mathrm{ml}$ of methanol) and the $\%$ relative standard deviation (\% RSD) at each level was determined. The robustness of the method was evaluated by deliberately varying the flow rate of mobile phase (1.9, 2.0 and $2.1 \mathrm{ml} / \mathrm{min}$ ), column oven temperature $\left(27,28\right.$ and $\left.29^{\circ} \mathrm{C}\right)$ and detection wavelength $(278,279$ and $280 \mathrm{~nm})$ and their effects on retention time, RSD of area and \% w/w of catechin in the sample were checked. For each condition, six injections of the standard solution $(40 \mu \mathrm{g} / \mathrm{ml})$ and two injections of sample (25 $\mathrm{mg}$ in $10 \mathrm{ml}$ of methanol) were applied.

\section{Stability studies of catechin solution}

Stability of the sample solutions was evaluated at different time interval such as 24,48 and $72 \mathrm{hr}$ after preparation and storage at $4.0^{\circ} \mathrm{C}$ and $25.0^{\circ} \mathrm{C}$ separately. Stability was checked by comparing the results of the solutions after storage with that of freshly prepared solutions.

\section{Quantification of catechin in extracts and polyherbal formulations by developed HPLC method}

The developed method was applied for quantitative determination of catechin in three different extracts and antiasthmatic polyherbal formulations containing Albizia lebbeck. The three extracts were prepared from bark obtained from three different geographical sources of India (Gujarat, Tamil Nadu and Maharashtra) to identify content variation of catechin.

\section{RESULTS AND DISCUSSION Method validation}

In this work, new, sensitive and time-saving HPLCDAD method was developed for estimation of catechin in Albizia lebbeck and validated as per ICH guidelines. Acceptable separation of catechin from other components present in methanol extract was achieved (Figure 1 and Figure 2). Catechin eluted at mean retention time of $1.79 \pm 0.20 \mathrm{~min}$ and total run time was $9 \mathrm{~min}$. Detection wavelength was selected at $279 \mathrm{~nm}$ which is $\boldsymbol{\lambda}_{\max }$ of catechin. The developed method was also found to be suitable for analysis of catechin with resolution greater than 1.9 , peak asymmetry 1.26, theoretical plates greater than 6600 and \% RSD less than 2.0. The method was found to be linear over the proposed range $3.0-60 \mu \mathrm{g} / \mathrm{ml}$ with linear regression

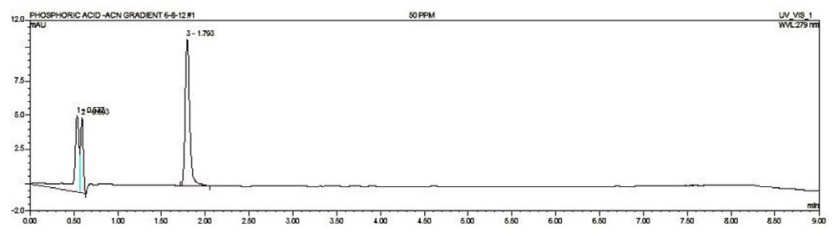

Figure 1: HPLC chromatogram of standard catechin.

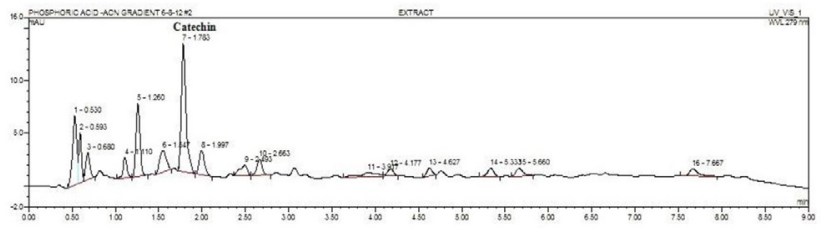

Figure 2: HPLC chromatogram of methanol extract of Albizia lebbeck. 


\begin{tabular}{|c|c|c|c|}
\hline Component & $\begin{array}{c}\text { Amount } \\
\text { Present }^{\mathrm{a}} \\
(\mu \mathrm{g} / \mathrm{ml}) \pm S . D .\end{array}$ & $\begin{array}{c}\text { Amount } \\
\text { Found }^{\mathrm{a}} \\
(\mu \mathrm{g} / \mathrm{ml}) \pm S . D .\end{array}$ & 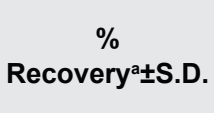 \\
\hline \multirow{3}{*}{ Catechin } & $32.8225 \pm 0.26$ & $32.0779 \pm 0.29$ & $97.7335 \pm 0.92$ \\
\hline & $40.8709 \pm 0.44$ & $39.6908 \pm 0.21$ & $97.1240 \pm 1.57$ \\
\hline & $48.9220 \pm 0.62$ & $48.9381 \pm 0.59$ & $100.0417 \pm 1.58$ \\
\hline
\end{tabular}

${ }^{a} n=3$, triplicate injections

\begin{tabular}{|c|c|c|c|c|}
\hline Component & $\begin{array}{c}\text { Amount } \\
\text { level } \\
\text { (mg/10 ml) }\end{array}$ & \multicolumn{2}{|c|}{$\begin{array}{l}\text { Intra day } \\
\text { (\% RSD) }^{\mathrm{b}}\end{array}$} & \multirow{2}{*}{$\begin{array}{c}\begin{array}{c}\text { Inter day } \\
\text { (\% RSD) }^{\mathrm{b}}\end{array} \\
\text { Day } 2\end{array}$} \\
\hline \multirow{4}{*}{ Catechin } & & Day 1 & Day 1 & \\
\hline & 20.0 & 0.9302 & 0.8226 & 0.6422 \\
\hline & 25.0 & 0.9047 & 1.2849 & 0.9469 \\
\hline & 30.0 & 0.6012 & 0.7272 & 1.0727 \\
\hline
\end{tabular}

${ }^{\mathrm{b}} n=3$, triplicate injections

\section{Table 3: Results of robustness studies for catechin.}

\begin{tabular}{|c|c|c|c|c|}
\hline Parameters & $\begin{array}{c}\text { Retention } \\
\text { time (Rt) }\end{array}$ & Area & $\%$ RSD $^{\mathbf{c}}$ & $\begin{array}{c}\text { \% w/w of } \\
\text { catechin }^{c}\end{array}$ \\
\hline \multicolumn{5}{|c|}{ Detection wavelength (nm) } \\
\hline 278 & 1.905 & 0.5049 & 1.2081 & 1.2459 \\
\hline 279 & 1.905 & 0.5062 & 1.6788 & 1.2433 \\
\hline 280 & 1.905 & 0.5019 & 1.7134 & 1.2406 \\
\hline \multicolumn{5}{|c|}{ Flow rate ( ml/min) } \\
\hline 1.9 & 1.997 & 0.5422 & 1.9365 & 1.1907 \\
\hline 2.0 & 1.905 & 0.5062 & 1.6788 & 1.2433 \\
\hline 2.1 & 1.816 & 0.4933 & 1.9258 & 1.2481 \\
\hline \multicolumn{5}{|c|}{ Column oven temperature (oC) } \\
\hline 27 & 1.930 & 0.5129 & 1.1503 & 1.2204 \\
\hline 28 & 1.905 & 0.5062 & 1.6788 & 1.2433 \\
\hline 29 & 1.832 & 0.5092 & 0.6087 & 1.2302 \\
\hline
\end{tabular}

${ }^{c} n=6$, six injections

coefficients $\left(R^{2}\right)$ of 0.9998 for the compound studied, demonstrating an acceptable data fit to the regression line $(y=0.0124 x+0.0066)$. The method was found be sensitive as it could detect $(\mathrm{LOD}=1.0 \mu \mathrm{g} / \mathrm{ml})$ and quantitate $(\mathrm{LOQ}=3.0 \mu \mathrm{g} / \mathrm{ml}$ ) lower amount of the compound. The accuracy of the standard in the spiked sample was evaluated at low, medium and high levels with mean recoveries of $97.73 \%, 97.12 \%$ and $100.04 \%$, respectively. In all levels of accuracy study, $\%$ RSD was less than 2.0 (Table 1).

The values of \% RSD are below 2.0 at all three levels of concentrations for both intraday and interday

\begin{tabular}{|c|c|c|}
\hline \multicolumn{2}{|c|}{ Table 4: \% w/w of catechin in extracts and } \\
formulations. \\
$\begin{array}{c}\text { Extracts / } \\
\text { Formulations }\end{array}$ & $\begin{array}{c}\text { \% w/w of } \\
\text { catechin }{ }^{\text {d }} \pm \\
\text { S.D. }\end{array}$ & mg of catechin ${ }^{\text {d }} \pm$ S.D. \\
\hline Extract-I (Gujarat) & $1.2575 \pm 0.00$ & $12.5750 \pm 0.00 / g$ of extract \\
\hline $\begin{array}{c}\text { Extract-II } \\
\text { (Tamilnadu) }\end{array}$ & $0.0939 \pm 0.00$ & $0.9390 \pm 0.00 / g$ of extract \\
\hline $\begin{array}{c}\text { Extract-III } \\
\text { (Maharashtra) }\end{array}$ & $0.0212 \pm 0.00$ & $0.2120 \pm 0.00 / g$ of extract \\
\hline Granules & $0.1723 \pm 0.02$ & $1.0592 \pm 0.13 /$ Teaspoon \\
\hline Herbal Tea & $0.3853 \pm 0.01$ & $0.7018 \pm 0.02 /$ Teaspoon \\
\hline Vati & $0.5628 \pm 0.00$ & $0.0508 \pm 0.00 /$ Vati \\
\hline Syrup & $0.0132 \pm 0.00$ & $0.2382 \pm 0.02 / T e a s p o o n$ \\
\hline
\end{tabular}

${ }^{\mathrm{d}} n=3$, triplicate injections

precision studies indicating that the method was precise (Table 2).

The robustness was estimated using the overall mean, standard deviation and \% RSD for each variable. $\%$ RSD was lower than 2.0 for the variables such as detection wavelength, flow rate and column oven temperature. The present method was found to be robust for the $\% \mathrm{w} / \mathrm{w}$ of catechin present in the sample (Table 3).

Stability of catechin in the sample solutions was evaluated at $4.0^{\circ} \mathrm{C}$ and $25.0^{\circ} \mathrm{C}$ for 3 consecutive days to check for degradation if any. The results were evaluated as the percentage of non-degraded catechin at defined time intervals. Both samples showed less than $4 \%$ degradation confirming that the samples were stable at $4.0^{\circ} \mathrm{C}$ and $25.0^{\circ} \mathrm{C}$ for 3 days.

\section{Quantification of catechin in extracts and polyherbal formulations containing Albizia lebbeck}

The developed method was applied for quantitative determination of catechin in three different methanol bark extracts and marketed polyherbal formulations containing Albizia lebbeck (Table 4). Amount of catechin was significantly higher in extract-I (Gujarat) as compared to extract-II and extract-III. In analysis of formulations, catechin content was highest in Vati as compared to other formulations. Thus, this method has justified its use in the quality control of polyherbal formulations prepared using bark of Albizia lebbeck.

\section{CONCLUSION}

Rapid, sensitive, selective, precise and accurate HPLCDAD method has been developed and validated for quantifying catechin in Albizia lebbeck extracts without 
requiring special sample preparation technique. The developed and validated method can be useful for standardization of anti-asthmatic polyherbal formulations containing Albizia lebbeck.

\section{ACKNOWLEDGEMENT}

Authors are thankful to National Medicinal Plants Board (NMPB), Department of AYUSH, New Delhi for financial assistance.

\section{CONFLICT OF INTEREST}

Authors declare that there are no conflict of interest.

\section{ABBREVIATIONS}

DAD: Diode Array Detector; LOD: Limit of Detection; LOQ: Limit of Quantification; OPA: Ortho Phosphoric Acid; HPLC: High Performance Liquid Chromatography; ICH: International Conferences on Harmonization; RSD: Relative Standard Deviation; SD: Standard Deviation; TFA: Trifluoro Acetic Acid; UV: Ultra Violet.

\section{REFERENCES}

1. Chopra RN, Badhwar RL, Ghosh S. Poisonous plants of India. Scientific Publishers: New Delhi. 1984

2. Chulet R, Pradhan P, Kaushik N. Pharmacognostical potential of Albizia lebbeck Benth. Pharm Expt. 2010;2.

3. Venkatesh P, Mukherjee PK, Kumar NS, Bandyopadhyay A, Fukui H, Mizuguchi $\mathrm{H}$, et al. Anti-allergic activity of standardized extract of Albizia lebbeck with reference to catechin as a phytomarker. Immunopharmacol Immunotoxicol. 2010;32(2):272-6.
4. Kajaria DK, Gangwar M, Kumar D, Sharma AK, Tilak R, Nath G, et al. Evaluation of antimicrobial activity and bronchodialator effect of a polyherbal drug-Shrishadi. Asian Pac J Trop Biomed. 2012;2(11):905-9.

5. Saito ST, Welzel A, Suyenaga ES, Bueno F. A method for fast determination of epigallocatechin gallate (EGCG), epicatechin (EC), catechin (C) and caffeine (CAF) in green tea using HPLC. Food Sci Technol. 2006;26(2):394-400.

6. Trox J, Vadivel V, Vetter W, Stuetz W, Kammerer DR, Carle R, et al. Catechin and epicatechin in testa and their association with bioactive compounds in kernels of cashew nut (Anacardium occidentale L.). Food Chem. 2011;128(4):1094-9.

7. Chu KO, Wang CC, Rogers MS, Choy KW, Pang CP. Determination of catechins and catechin gallates in biological fluids by HPLC with coulometric array detection and solid phase extraction. Anal Chim Acta. 2004;510(1):69-76.

8. Soares LA, Oliveira AL, Ortega GG, Petrovick PR. Development and validation of a LC-method for determination of catechin and epicatechin in aqueous extractives from leaves of Maytenus ilicifolia. J Pharm Biomed Anal. 2004;36(4):787-90.

9. Zu Y, Li C, Fu Y, Zhao C. Simultaneous determination of catechin, rutin, quercetin kaempferol and isorhamnetin in the extract of sea buckthorn (Hippophae rhamnoides L.) leaves by RP-HPLC with DAD. J Pharm Biomed Anal. 2006;41(3):714-9.

10. Fracassetti D, Lawrence N, Tredoux AG, Tirelli A, Nieuwoudt HH, DuToit WJ. Quantification of glutathione, catechin and caffeic acid in grape juice and wine by a novel ultra-performance liquid chromatography method. Food Chem. 2011;128(4):1136-42.

11. Carando S, Teissedre PL, Cabanis JC. Comparison of (+)-catechin determination in human plasma by high-performance liquid chromatography with two types of detection: Fluorescence and ultraviolet. J Chromatogr B Biomed Sci Appl. 1998;707(1-2):195-201.

12. Chang CL, Wu RT. Quantification of $(+)$-catechin and (-)-epicatechin in coconut water by LC-MS. Food Chem. 2011;126(2):710-7.

13. Dubey N, Dubey N, Mehta R, Saluja A. A Selective High Performance Liquid Chromatographic Method for Estimation of Catechin in Ayurvedic Taila Preparations. Asian J Research Chem. 2009;2(1):66-9.

14. DeSouza DF, Lovillo MP, Barroso CG, David JM. Optimization and validation of a method for the direct determination of catechin and epicatechin in red wines by HPLC/fluorescence. Microchem J. 2010;96(1):17-20.

15. ICH Q2 (R1): Validation of analytical procedures: Text and methodology. In International Conference on Harmonization, Geneva. 2005.

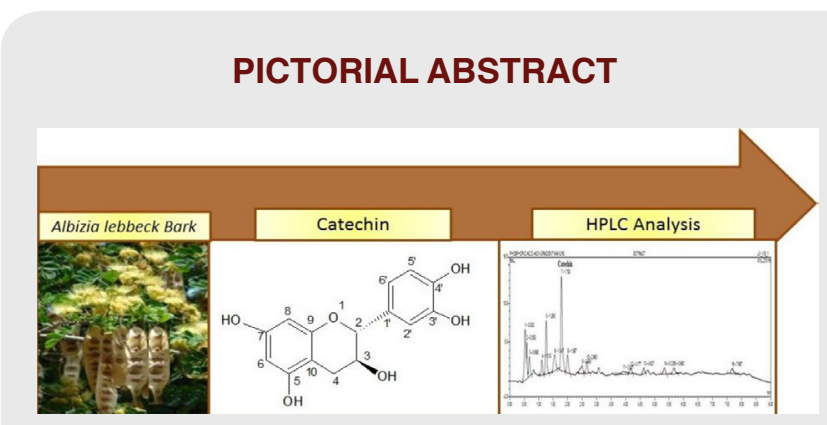

\section{SUMMARY}

Catechin was used as marker for marker-based standardization of extracts and polyherbal formulations containing Albizia lebbeck by HPLC. 


\section{About Authors}

Dr. Sonal Desai is currently working as Associate Professor and Head, Department of Quality Assurance, SSR College of Pharmacy, Silvassa, UT of Dadra and Nagar Haveli, India.

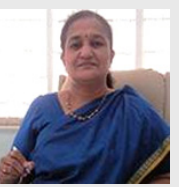

Dr. Pratima Tatke is currently working as Principal and Professor of Pharmaceutical Chemistry, C. U. Shah College of Pharmacy, SNDT Women's University, Mumbai, Maharashtra, India. Her area of research expertise is Phytochemistry, Analysis of Herbal products and Phytopharmacology.

Dr. Vinay Gaitonde is founder of Prochrome India Pvt. Ltd., Mumbai, Maharashtra, India.

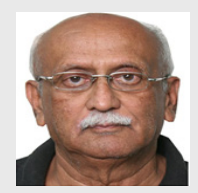

Dr. Satish Gabhe is currently working as Professor of Pharmaceutical Chemistry, Poona College of Pharmacy, Bharati Vidyapeeth (Deemed University), Pune, Maharashtra, India.

Cite this article: Desai S, Tatke P, Gaitonde V, Gabhe S. Fast HPLC-DAD Method for Estimation of Catechin for Standardization of Extracts and Antiasthmatic Polyherbal Formulations Containing Albizia lebbeck. Indian J of Pharmaceutical Education and Research. 2020;54(3):550-5. 